\title{
PERAN DAN FUNGSI SELF-ACCESS LEARNING CENTER DI UNY
}

\author{
Jamilah, Joko Priyana, dan Suciati \\ Universitas Negeri Yogyakarta \\ email: jamilah@uny.ac.id
}

\begin{abstract}
(Title: Role and Function of Self-Access Learning Center in UNY). This study aims to develop self-access reading materials for learning English independently. This research was conducted with the Research and Development model by following the steps: needs assessment, design and development, evaluation and revision, and a try out field. Data collected through questionnaires. There are three questionnaires used, namely for needs assessment, for expert judgment, and for field trials. Sample for needs assessment was taken by proportional quota sampling representing all faculties at UNY, while samples for the trial were taken purposively. The collected data was analyzed descriptively quantitatively. The results of the study showed that SAC UNY had not been widely known by students. Even after the introduction of online tutorials since 2015, the SAC is no longer visited by students. Thus the teaching materials developed should also be in the form of online. SAC socialization was also deemed necessary so that students were more familiar with the existence, function, and role of SAC in developing the English language skills of UNY students.
\end{abstract}

Keyword: SAC, teaching materials, language skills, English

\section{PENDAHULUAN}

Kemampuan Bahasa Inggris adalah modal utama para mahasiswa dalam pengembangan ilmu dan karir mereka dikemudian hari, oleh karenanya kemampuan Bahasa Inggris merupakan salah satu indicator mutu perguruan tinggi. Rendahnya kemampuan Bahasa Inggris mahasiswa sering dikeluhkan sebagai faktor penghambat dalam berbagai hal kehidupan akademik. Berbagai usaha peningkatan kamampuan Bahasa Inggris telah dilakukan, antara lain melalui matakuliah Bahasa Inggris MKU, Test TOEFL like dan berbagai layanan Bahasa oleh P2B. Namun demikian, usahausaha ini tidak akan banyak gunanya dalam peningkatan kemampuan Bahasa Inggris mahasiswa, manakala mereka sendiri tidak mau aktif berusaha. Keaktifan mahasiswa untuk meningkatkan kemampuan Bahasa Inggris secara mandiri ini perlu diupayakan jika perguruan tinggi punya komitmen untuk peningkatan mutu akademik.

Rendahnya keinginan mahasiswa untuk belajar Bahasa Inggris secara mandiri dipicu oleh banyak hal, antara lain, rasa malas, tidak ada fasilitas, dan tidak ada lingkungan yang mendorong mereka untuk belajar mandi- ri. Rasa malas hanya dapat diatasi oleh pribadi mereka sendiri, namun fasilitas dan lingkungan dapat diciptakan oleh lembaga ke arah tersebut. Pengembangan materi-materi ajar yang bagus, menarik dan sesuai kebutuhan mahasiswa adalah salah satu upaya penyediaan fasilitas belajar mandiri.

Sebenarnya sudah banyak tersedia materi ajar Bahasa Inggris yang dapat digunakan oleh siapa saja untuk belajar secara mandiri. Adanya berbagai literatur berbahasa Inggris di lingkungan mahasiswa telah memberikan exposure yang melimpah bagi mereka untukmempelajarinya. Namun literature-literatur seperti ini terkadang terlalu sulit bagi banyak mahasiswa sehingga menambah rasa enggan mereka untuk mencoba mempelajarinya.

Banyaknya materi ajar Bahasa Inggris online juga memungkinkan mahasiswa untuk belajar mandiri, namun kenyataannya sangat sedikit mahasiswa yang memanfaatkannya. Terlalu banyak godaan pada situs-situs Internet sehingga mahasiswa cenderung terbawa arus dan memilih kegiatan-kegiatan hiburan dan melupakan tujuan awalnya. Selain itu materi ajar yang ada di Internet juga terlalu banyak se- 
hingga unmanageable, terlalu sulit dan kurang sesuai dengan kebutuhan.

Belum dimanfaatkannya Self Access Center (SAC) yang ada di Pusat Pengembangan Bahasa juga merupakan masalah. Banyak faktor menjadi penyebabnya. Belum cukup luas sosialisasi SAC, kurang menarik, atau bahkan kurang materi yang dapat diakses. Tempat belajar mandiri yang sudah tersedia seyogyanya dilengkapi dengan materi-materi belajar yang banyak dan menarik. Pengembangan materi SAC yang baik merupakan kebutuhan mendesak yang harus segera dipenuhi setahap-demi setahap. Pertanyaan penelitian yang diajukan dalam penelitian ini adalah, sudahkah SAC di UNY berfungsi dengan baik dan telah dimanfaatkan oleh mahasiswa untuk meningkatkan kemampuan Bahasa Inggris mereka?

Bahasa adalah alat komunikasi dan untuk menguasainya pembelajar perlu menguasai kemampuan komunikatif yang oleh Bahman (1990) dikatakan mencakup tiga komponen yaitu language competence, strategic competence, dan psychophysical mechanism. Untuk menguasai kemampuan komunikatif, pendekatan komunikatif perlu diterapkan dalam pembelajaran (Richards, 2006). Menurutnya, pembelajaran komunikatif antara lain dicirikan dengan adanya otonomi pelajar, yaitu pelajar memiliki otonomi lebih besar untuk menentukan sendiri apa yang akan mereka pelajari dan bagaimana mempelajarinya.

Nation (2010) menyatakan bahwa untuk dapat menguasai kemampuan berbahasa asing pelajar perlu mendapatkan input Bahasa yang melimpah dan bermakna, mempelajari bentuk Bahasa secara rinci, menggunakan Bahasa untuk berkomunikasi, dan latihan terus menerusdalam empat keterampilan sehingga timbul otomatisasi dalam penggunaan Bahasa. Nation menamakan empat bidang ini dengan the four strands of language learning yang mencakup meaning focus input, form focus learning, meaning focus output dan fluency development. Pembelajaran di kelas lebih banyak menyajikan aspek form focus learning, input dan out secara terbatas, dan sangat sedikit untuk fluency development. Kurangnya input yang melimpah dan bermakna dan kurangnya fluency development inilah yang sangat mem batasi pengembangan kemampuan Bahasa asing termasuk Bahasa Inggris.

Untuk menyediakan input yang melimpah dan bermakna dan sekaligus memberikan fasilitas untuk fluency development, bahan-bahan bacaan yang sesuai dengan tingkat kemampuan dan minat pembelajar perlu disediakan.

Self-access learning materials adalah materi-materi ajar Bahasa Inggris yang didisain untuk digunakan untuk belajar mandiri. Materi-materi seperti ini biasanya banyak ditemukan di SAC (self-accesscentres). SAC biasa dikenal dengan nama-nama lain sepertiindependent learning centres atau open learning centres. Ada banyak jenis materi ajar Bahasa Inggris yang dapat ditemukan di tempat seperti ini, seperti misalnya materi bacaan otentik dari majalah, Koran, program TV, film dan musik; graded readers, language learning softwarel web-based resources, coursebooks, texts for specific skills, dan teks-teks untuk persiapan ujian (Cooker,2008).

Self-access reading materials adalah materi ajar untuk pengembangan keterampilan membaca yang dapat dipelajari sendiri oleh mahasiswa. Karena materi-materi seperti ini digunakan tanpa pendampingan tutor, banyak syarat-syarat yang harus dipenuhi agar dapat berfungsi dengan baik. Menurut Cooker (2008) syarat-syarat tersebut meliputi: 1 . Instruksi harus jelas, 2) level bahasa dideskripsikan dengan jelas, 3) penampilan menarik, 4) menyediakan banyak latihan, 5) menyediakan feedback (kunci jawaban), 6) Memudahkan mahasiswa menemukan apa yang mereka perlukan, 7) memberikan banyak contoh, dan 8) menjelaskan bagaimana cara melakukannya/ mengerjakan dengan cara terbaik (Reinders \& Lewis, 2006).

Materi ajar reading dikembangkan berdasarkan kaidah pembelajaran reading. Dengan demikian perlu dikaji terlebih dahulu apa hakekat membaca, dan subskills apa saja yang harus dikembangkan dalam materi ajar membaca.

Membaca secara sederhana dapat didefnisikan sebagai kegiatan menemukan informasi atau pesan dari teks tertulis atau bentuk visual lainnya. Menurut Stoller dan Grabe 
(2011) definisi sederhana ini masih belum memadai karena belum mempertimbangkan adanya berbagai tujuan membaca, belum mempertimbangkan adanya berbagai proses yang terlibat dalam membaca lancar, tidak menjelaskan bahwa membaca adalah kegiatan kognitif yang sangat cepat, tidak mempertimbangkan adanya berbagai ragam kemampuan membaca siswa, dan yang terakhir tidak menjelaskan konteks sosial dari kegiatan membaca. Pengertian membaca tidak dapat dijelaskan dengan satu kalimat saja, melainkan harus dijelaskan dari berbagai macam aspek, seperti dari aspek tujuannya, komponen-komponen yang terlibat dalam proses membaca, dan proses-proses yang diperlukan untuk dapat membaca denganlancar.

Berdasarkan tujuannya, Stoller dan Grabe (2011: 6) mengklasifikasikan tujuan membaca menjadi tujuh, yaitu: 1) membaca untuk menemukan informasi sederhana, 2) membaca untuk menemukan fakta dengan cepat, 3) membaca untuk belajar dari teks, 4) membaca untuk menyatukan informasi, 5) membaca untuk menulis, 6) membaca untuk mengkritisi teks, dan 7) membaca untuk pemahaman umum. Dalam konteks EAP, tujuan dari kegiatan membaca bisa beragam, baik untuk belajar, menyatukan informasi, mengkritisi teks, untuk menulis, maupun untuk pemahaman umum.

Stoller dan Grabe (2011: 129) menyatakan bahwa keterampilan membaca sangat penting dalam konteks akademik. Dalam konteks ini, membaca berperan sangat signifikan karena merupakan sumber input utama bagi siswa untuk belajar lebih lanjut, baik terkait dengan belajar bahasa maupun isi atau informasinya. Selain itu, membaca juga mampu menumbuhkan minat dan motivasi bagi siswa untuk menggali informasi-informasi lain melalui bacaan-bacaan tambahan. Namun demikian, keterampilan membaca tidak datang dengan sendirinya, melainkan memerlukan penguasaan kosakata cukup banyak, penguasaan grammar yang mencukupi, dan strategistrategi yang diperlukan dalam kegiatan membaca yang efektif. Untuk itu membaca harus diajarkan dengan baik.

Grabe dan Stoller (2011: 130) menyatakan bahwa untuk dapat membaca dengan terampil, pembelajar perlu menguasai kemampuan-kemampuan berikut: (a) decode graphic forms for efficient word recognition, (b) access the meanings of a large number of words automatically, (c) draw meaning from phraseand clause-level grammatical information, (d) combine clause-level meanings into larger networks of text comprehension, (e) recognize discourse structures that build and support comprehension, (f) use reading strategies for a range of academic reading tasks, (g) set goals for reading and adjust them as needed, (h) use inferences of various types and monitor comprehension for reading goals, (i) draw on prior knowledge as appropriate, (j) evaluate, integrate and synthesize information for critical reading comprehension, $(\mathrm{k})$ maintain these processes fluently for extended period of time, and sustain motivation to persist in reading and use text information for reading goals.

Dari sub-skill tersebut diatas sebagian telah dikuasai mahasiswa mengingat huruf atau tulisan yang digunakan Bahasa Inggris sama dengan Bahasa Indonesia, namun demikian aspek kebahasaan dan kelancaran masih perlu pengembangan terus menerus. Materi kebahasaan seperti pengembangan kosa kata dan pemahaman menjadi fokus dalam materi ajar reading.

Materi ajar reading dapat disajikan dengan berbagai pendekatan, top down, bottom up, ataupun interactive model. Materi yang dikembangkan akan disusun dengan model top-down yang akan menggunakan urutan prereading, while-reading, language focus, dan Post-reading.

\section{METODE}

Penelitian ini adalah langkah pertama dari R \& D, yaitu tahap analisis kebutuhan belajar di SAC. Teknik yang diterapkan berupa survey, dengan kuesioner sebagai alat utama pengumpulan data. Penelitian dilakukan di UNY yang melibatkan seluruh fakultas yang ada di UNY. Subyek yang terlibat adalah mahasiswa UNY. Responden untuk needs analisis diambil secara acak proporsional yang merefleksikan seluruh fakultas di UNY.

Data dikumpulkan dengan kuesioner, yaitu kuesioner analisis kebutuhan. Data yang 
terkumpul dianalisis secara deskriptif kuantitatif, dengan persentase

Kuesioner untuk Needs assessment dibuat dengan model skala Likert yang dikembangkan berdasarkan teori-teori yang digunakan, antara lain berdasar Allan \& Waters (1997), Staller \& Grabe (2011) and Nunan (2004).

\section{HASIL DAN PEMBAHASAN Deskripsi SAC diUNY}

Di UNY terdapat dua SAC yaitu satu unit berada di FBS dan yang lain berada di LPPMP. SAC yang berada di FBS dinamakan SALC (Self Access Learning Center) sedangkan yang berada di LPPMP dinamakan IELLC (Independent English Language Learning Center). SALC yang ada di FBS didirikan terutama untuk memfasilitasi mahasiswa Jurusan Bahasa Inggris dalam belajar mandiri, sedangkan IELLC dibawah LPPMP diperuntukkan bagi semua mahasiswa UNY bahkan di luar UNY yang belajar Bahasa Inggris di Pusat Pelayanan Bahasa (P2B) UNY untuk meningkatkan kemampuan Bahasa Inggris mereka dengan cara belajarmandiri.

SALCFBS berada di Gedung Kuliah 4 Lantai 3,didirikan pada tahun 2008 atas dana hibah A2. SALC memiliki koleksi buku-buku pembelajaran Bahasa Inggris yang terbatas dan terbitan lama. Selain koleksi buku, terdapat pula sumber belajar dalam bentuk $C D$ atau sumber-sumber belajar online, dan beberapa unit komputer yang sudah tua pula. Pusat belajar Bahasa Inggris ini tidak mendapatkan tambahan koleksi karena memang SALC tidak memiliki sumber dana dan hanya mendapatkan alokasi dana dari fakultas yang sangat terbatas. SALC dikelola oleh seorang kepala dan dibantu oleh beberapa mahasiswa secara sukarela. Mereka tidak mendapatkan honor maupun fasilitas yang lain, sehingga tidak mengherankan jika kondisi SALC sebagai sarana belajar Bahasa Inggris mandiri yang sangat dibutuhkan oleh mahasiswa ini kondisinya sangat memprihatinkan.

IELLC yang berada di LPPM dan dikelola oleh P2B memiliki organisasai yang sedikit lebih baik dari pada SALC UNY. Di bawah koordinasi ketua P2B, IELLC menempati sebuah ruang di lantai pertama gedung
LPPMP sayap barat. Pusat belajar ini memiliki beberapa orang petugas yang memberikan pelayanan setiap hari kerja. Pada hari Senin sampai dengan Kamis pusat belajar ini dibuka sejak jam 7.30 dan ditutup pada jam 15.00, sedangkan pada hari Jumat tutup pada jam14.

Pusat belajar Bahasa Inggris mandiri ini memiliki koleksi sumber belajar berupa: (a) koleksi buku (General English, Speaking, Writing, English for Specific Purposes books, dsb.) dalam judul dan jumlah terbatas; (b) Self-access learning materials (TOEFL, IELTS, TOIEC, Reading, Listening, Grammar, dsb.), dalam judul dan jumlah terbatas, terakhir dibuat tahun 2013, dan (c) Selain itu, IELLC juga mempunyai layanan tutorial, speaking club, language clinic dan mobile learning).

Koleksi perpustakaan IELLC merupakan koleksi lama, karena penambahan koleksi mengalami kendala keterbatasan anggaran. Materi self access masih sangat sedikit, baik dari segi jumlah dan topik. Sejak tahun 2013 hingga kini belum ada pemutakhiran materimateri belajar self-access.

Selain kondisi sumber belajar yang masih sangat terbatas kondisi ruangan juga tidak jauh berbeda. Kondisi ruang saat ini kurang nyaman karena masih bercampur antara ruang tutor dan admin IELLC, perpustakaan, dan ruang kelas. Komputer hanya ada 1 buah untuk anggota IELLC. Kondisi ini barangkali karena P2B belum memiliki gedungtersendiri.

Pusat belajar Bahasa Inggris ini pernah ramai dikunjungi oleh mahasiswa yang ingin belajar Bahasa Inggris secara mandiri, namun sudah sekitar 3 tahun terakhir ini, yaitu sejak diberlakukannya kelas-kelas online untuk kegiatan tutorial, tempat ini tidak lagi dikunjungi oleh mahasiswa.

Selain kondisi tempat maupun sumber belajar, SAC di UNY juga sangat memprihatinkan dari sisi kepopulerannya dikalangan mahasiswa. Untuk dapat berfungsi dengan baik, sebuah pusat belajar haruslah dikenal dengan baik oleh para penggunanya. Namun tidak demikian halnya dengan SAC yang ada di UNY. Berdasarkan data dari kuesioner yang telah diisi oleh mahasiswa, sedikit sekali mahasiswa yang mengetahui adanya SAC di UNY. Dari 299 responden hanya 22\% dari mereka 
yang mengetahui adanya SAC, dan $78 \%$ lainnya menyatakan bahwa mereka tidak mengetahuinya.

\section{Analisis Kebutuhan Belajar diSAC}

Analisis kebutuhan belajar Bahasa Inggris mandiri ini didasarkan pada kuesioner yang telah diisi oleh 299 mahasiswa UNY pada bulan Juni dan Juli 2018. Kuesioner online telah di-upload dan mendapat respon dari 299 mahasiswa dari semua fakultas yang ada di UNY dan dari berbagai angkatan mulai dari angkatan tahun 2013 sampai dengan2017. Sebagian besar responden $(72,6 \%)$ berjenis kelamin wanita, dan hanya $(27,4 \%)$ laki-laki.

Dari 299 responden yang mengisi kuesioner, skor TOEFL mereka tergolong masih rendah,dengan rerata sikitar 425, dengan demikian mereka sesungguhnya masih memerlukan belajar mandiri lebih banyak. Berikut adalah daftar skor TOEFL mereka.

Tabel 1. Skor TOEFL Responden

\begin{tabular}{lcc}
\hline Skor TOEFL & Frekuensi & Persent \\
\hline Di atas 600 & 1 & 0,3 \\
550 s/d 599 & 1 & 0,3 \\
500 s/d 549 & 11 & 3,6 \\
450 s/d 499 & 52 & 17,3 \\
400 s/d 449 & 174 & 58,2 \\
350 s/d 399 & 31 & 10,3 \\
\hline
\end{tabular}

Telah dikatakan sebelumnya bahwa sebagian besar dari mereka (78\%) tidak mengetahui adanya SAC di UNY, hanya $22 \%$ dari mereka yang tahu adanya SAC di UNY. Namun mereka 94,3 menyatakan membutuhkan adanya SAC untuk belajar mandiri.

Mereka mengetahui adanya SAC dari teman, dari dosen, internet/website, kegiatan terkait protefl (tes/tutorial), dan pembekalan mahasiswa baru.

Dari sekian banyak responden hanya $7 \%$ yang pernah berkunjung ke SAC, lainnya belum pernah. Artinya keberadaan SAC di UNY belum banyak diketahui oleh mahasiswa dan sedikit sekali mahasiswa UNY yang pernah berkunjung ke SAC.

$7 \%$ responden yang pernah berkunjung ke IELLC, menyatakan bahwa mereka melakukan tes ProTEFL, Tutorial ProTEFL, nonton film dan net surfing.

Dari mereka yang pernah berkunjung ke IELLC, mereka menyatakan bahwa layanan di IELLC termasuk cukup memuaskan $(76,5)$. Mereka juga menyatakan bahwa kualitas sumber belajar termasuk cukup baik $(77,1)$. Mereka menyarankan, agar IELLC meningkatkan kualitas pelayanan dan memperbarui koleksi sumber ajar. Mereka juga menyarankan agar ada layanan bagi orang-orang berkebutuhan khusus. Jika mereka akan belajar Bahasa Inggris mandiri melalui SAC, mereka memerlukan layanan sebagai berikut.

Tabel 2. Layanan SAC yang diperlukan mahasiswa

\begin{tabular}{clc}
\hline No & \multicolumn{1}{c}{ Layanan } & Persentase \\
\hline 1 & Speaking club & 76 \\
2 & Tutorial & 56 \\
3 & Klinik Bahasa & 54,3 \\
4 & Online learning & 50,7 \\
5 & Writing & 0,4 \\
6 & Grammar & 0,4 \\
\hline
\end{tabular}

Selain layanan, mahasiswa juga memerlukan sumber belajar yang meliputi bukubuku terkait dengan Bahasa Inggris terstandar, buku-buku pelajaran Bahasa Inggris pada umumnya, materi untuk belajar mandiri, $\mathrm{CD}$ dan program-program belajar bahasa Inggris online, danVideo.

Tabel 3. Sumber belajar yang diperlukan mahasiswa

\begin{tabular}{clc}
\hline No & Sumber Belajar & Persentase \\
\hline 1 & $\begin{array}{l}\text { Buku-buku terkait dengan } \\
\text { test bahasa Inggris }\end{array}$ & 15,8 \\
& $\begin{array}{l}\text { Buku-buku untuk belajar } \\
2\end{array}$ & $\begin{array}{l}\text { Bahasa Inggris pada } \\
\text { umumnya }\end{array}$ \\
3 & Materi untuk belajar mandiri & 15,3 \\
4 & Video & 11,3 \\
5 & Sofware/CD pembelajaran & 11,1 \\
\hline
\end{tabular}

Untuk dapat menunjang belajar mandiri mereka, para mahasiswa memerlukan fasili- 
tas yang meliputi Internet access, Listening corner, movie and TV corner, computer, ruang baca, dan ruang diskusi.

Tabel 4. Fasilitas belajar yang diperlukan mahasiswa

\begin{tabular}{clc}
\hline No. & \multicolumn{1}{c}{ Fasilitas } & Persentase \\
\hline 1 & Internet access & 19,6 \\
2 & Listening corner & 18,5 \\
3 & Movie and TV corner & 18,3 \\
4 & Computer & 15,3 \\
5 & Ruang baca & 14,8 \\
6 & Ruang diskusi & 13,7 \\
\hline
\end{tabular}

Selain fasilitas belajar pada umumnya, berikut ditemukan pula kebutuhan belajar membaca. Kebutuhan membaca ini meliputi tema yang diinginkan mahasiswa, jenis teks, panjang teks, kegiatan membaca yang diinginkan

Tabel 5. Tema apa yang diinginkan mahasiswa

\begin{tabular}{|c|c|c|}
\hline No & Tema & Persentase \\
\hline 1 & Sosial & 32,5 \\
\hline 2 & Humaniora & 23,6 \\
\hline 3 & Akademik & 16,2 \\
\hline 4 & Sport & 14,9 \\
\hline 5 & Sain & 12,1 \\
\hline
\end{tabular}

Keterampilan membaca yang mereka perlukan adalah keterampilan membaca akademik atau reading for information, yang meliputi menemukan topik bacaan, gagasan pokok teks, informasi detil tersurat, informasi tersirat. Strategi membaca yang mereka inginkan meliputi menghubungkan peristiwa dalam bacaan $(15,2 \%)$, membuat dugaan untuk menemukan makna tersirat $(15,2 \%)$, menemukan informasi rinci $(15 \%)$, mengetahui struktur teks $(15 \%)$, baru diikuti aktivitas menanya(12\%).

Aktivitas membaca yang mereka inginkan berupa kegiatan membaca yang diikuti dengan menjawab pertanyaan $(59,5 \%)$, mengidentifikasi gagasan pokok teks $(47,2 \%)$, menganalisis teks $(41,5 \%)$, dan meringkas bacaan $(26,4 \%)$.

Karena kegiatan ini berupa kegiatan belajar mandiri mereka juga menginginkan kegiatan membaca yang dilakukan sendiri, atau mencari informasi secara mandiri namun masih ada kegiatan sharing hasil kegiatan membaca dengan teman baik secara berkelompok dalam kelas, kelompok kecil maupun berpasangan.

Jenis teks yang ingin mereka baca meliputi teks deskriptif (26,9\%), narrative $(21,4 \%)$, argumentative $(12,2 \%)$, procedure $(11,9)$, report $(9,2 \%)$, baru diikuti expository, discussion, dan recount.

Panjang teks yang paling mereka ingin baca adalah antara 400 sampai dengan 500 kata $(42,5 \%)$, kurang dari 400 kata $(30,4 \%)$, antara 500 sampai dengan 600 kata $(17,1 \%)$ dan yang menginginkan teks dengan panjang di atas 600 kata hanya sebesar $10 \%$ saja.

\section{Kesulitan yang dihadapi mahasiswa dan harapan yang ingin mereka capai}

Mahasiswa menyatakan bahwa mereka masih menghadapi kesulitan membaca yang disebabkan oleh berbagai hal, yaitu, terbatasnya kosakata $(84,6 \%)$, terbatasnya penguasaan grammar $(77,9 \%)$, terbatasnya pengetahuan tentang struktur teks $(46,2 \%)$, dan terbatasnya pengetahuan tentang topik bacaan (38\%).

Untuk mempermudah pemahaman bacaan karena masih ditemukannya berbagai kendala, gambar dapat dimanfaatkan untuk tujuan itu. $86 \%$ responden menyatakan bahwa gambar sangat penting untuk membantu pemahaman,sedangkan 16\% yang lain menyatakan kurang membantu.

Dari kesulitan-kesulitan yang mereka hadapi ini mereka berharap dengan kegiatan mendiri ini mahasiswa akan mendapat manfaat berupa peningkatan kosa kata $(86,6 \%)$, dapat memahami teks dengan baik $(66,9 \%)$, dapat menggunakan Bahasa yang digunakan dalam teks $(62,5 \%)$, dandapat membaca dengan lebih lancer $(60,2 \%)$.

Meskipun mahasiswa merasa perlu untuk membaca mandiri agar kemampuan membaca mereka meningkat, waktu yang mereka sediakan untuk membaca mandiri ternyata tidak begitu banyak. Sebagian besar $(58,2 \%)$ hanya menyediakan waktu kurang dari satu jam setiap minggunya untuk membaca mandiri, $24,7 \%$ menyediakan waktu sekitar 1 sampai 1,5 jam, dan hanya sekitar $15 \%$ menyediakan 
waktu di atas satu setengah jam setiap minggunya untuk membaca mandiri.

Terkait dengan fasilitas internet, responden menyatakan bahwa mereka memiliki akses internet baik dengan menggunakan handphone, wifi, atau internet di rumah. Hanya $1 \%$ yang menyatakan tidak memiliki akses internet. Dengan kondisi ini kegiatan-kegiatan belajar online sangat dimungkinkan.

Keberadaan SAC yang sejatinya sangat penting dalam peningkatan kemampuan Bahasa Inggris secara mandiri di UNY masih belum banyak diketahui oleh mahasiswa. Sedikit sekali mahasiswa yang mengetahui adanya SAC yang dapat mereka manfaatkan. Kurangnya pengetahuan mereka ini kemungkinan disebabkan kurangnya sosialisasi SAC kepada mahasiswa, kurang dimanfaatkannya SAC oleh dosen Bahasa Inggris dalam pembelajaran Bahasa mereka.

\section{SIMPULAN DAN SARAN}

UNY memiliki dua SAC (self access center/pusat belajar Bahasa Inggris mandiri), satu berada di FBS dan yang lain ada di LPPMP. Keduanya tidak banyak dikenal oleh mahasiswa. Sedikit sekali mahasiswa yang berkunjung SAC, dan kunjungan mereka ke SAC hanya sebatas untuk belajar mengerjakan soal-soal TOEFL. Nampaknya mahasiswa juga kurang memahami fungsi dan peran SAC dalam peningkatan kemampuan Bahasa Inggris.

UNY perlu mensosialisasikan keberadaan SAC baik yang ada di FBS maupun di LPPMP. UNY perlu mengembangkan SAC lebih baik lagi, misal dengan menambah koleksi bahan ajar, memberikan dukungan dana operasional sehari-hari, memperbaharui peralatan seperti komputer. UNY perlu memperbaiki manajemen SAC dan optimalisasi pemanfaatannya secara lebih baik dalam peningkatan kemampuan Bahasa Inggris mahasiswa.

\section{DAFTAR PUSTAKA}

Bahman, L.F. (1990). Fundamental consideration in language testing, Oxford: Oxford University Press

Cooker, L. (2008). Self-Access Materials in Tomlinson (2008). English Language Learning Materials, a Critical Review, London: Continuum.

Hutchinson, T. \& Waters, A. 1987. English for specific purposes, a Learning-centred approach. Cambridge: Cambridge University Press.

Mol, H., \& Tin, T. B. (2008). EAP materials in New Zealand and Australia dalam Tomlinson, B. (Ed) English language learning materials, London: Continuum International Publishing Group

Nation, I.S.P. \& Macalister, J. (2010). Language curriculum development. New York/London: Routledge.

Nation, I. S. P. (2012). What should every ESL teacher know? Compass Publishing.

Richards, J.C. (2006). Communicative language teaching Today. Cambridge: Cambridge University Press.

Tomlinson, B. (2008). English Language Learning Materials, a critical review. New York: Continuum.

Reinders, H. \& Lewis, M (2006). An Evaluative Checklist for self-access Materials, ELT Journal, 60, 272-278.

Richards, J.C. (2001). Curriculum development in language teaching. Cambridge: Cambridge University Press. 